\section{THU0299 AN INTEGRATED ANALYSIS OF CHANGES IN LIPID LEVELS AND INCIDENCE OF CARDIOVASCULAR EVENTS FOLLOWING TOFACITINIB TREATMENT IN PATIENTS WITH PSORIATIC ARTHRITIS ACROSS PHASE 3 AND LONG-TERM EXTENSION STUDIES}

${ }^{1}$ D.D. Gladman, C. Charles-Schoeman ${ }^{2}$, I.B. Mclnnes ${ }^{3}$, D.J. Veale ${ }^{4}$, B. Thiers ${ }^{5}$ D. Graham ${ }^{6}$, C. Wang ${ }^{6}$, T.V. Jones ${ }^{7}$, R. Wolk ${ }^{6}$, R. DeMasi ${ }^{7}{ }^{1}$ University of Toronto, Toronto Western Hospital, Toronto, ON, Canada; ' ${ }^{2}$ University of California, Los Angeles, CA, USA; ${ }^{3}$ University of Glasgow, Glasgow, UK; ${ }^{4}$ St. Vincent's University Hospital and University College Dublin, Dublin, Ireland; ${ }^{5}$ Medical University of South Carolina, Charleston, SC; ${ }^{6}$ Pfizer Inc, Groton, CT; ${ }^{7}$ Pfizer Inc, Collegeville, $P A, U S A$

Background: Cardiovascular (CV) disease and cardiometabolic syndrome are common comorbidities/causes of mortality in patients (pts) with psoriatic arthritis (PsA). Tofacitinib is an oral JAK inhibitor for the treatment of PsA.

Objectives: To investigate changes in lipid levels and incidence of $C V$ events in pts with PsA treated with tofacitinib in Phase (P) 3 and long-term extension (LTE) studies.

Methods: Data were analysed for pts who received $\geq 1$ dose of tofacitinib 5 or $10 \mathrm{mg}$ BID or placebo (PBO), integrated across $2 \mathrm{P} 3$ studies (OPAL Broaden [12 months (m); NCT01877668, including adalimumab control]; OPAL Beyond [6 m; NCT01882439]) and 1 LTE study (OPAL Balance [data cut-off May 2016; ongoing, database not locked; NCT01976364]). Lipid levels were assessed throughout P3 and LTE studies; this analysis included data from the PBO-controlled period (MO-3) of P3 studies. Blood pressure, hypertension events (standardised MedDRA query [narrow]) and adjudicated (independent/blinded to treatment) major adverse cardiovascular events (MACE) are reported for all pts who received $\geq 1$ dose of tofacitinib (pooled across doses for hypertension and MACE). Incidence rates (IR; pts with events/100 pt-years [PY]) and $95 \% \mathrm{Cl}$ are reported.

Results: Overall, 783 pts (776 PY of tofacitinib exposure) were included in P3 and LTE studies; treatment duration was 1-927 days. After $3 \mathrm{~m}$ of tofacitinib treatment in P3 studies, dose-dependent increases in lipid levels were observed with tofacitinib; minimal changes were observed with PBO, except for triglycerides (figure 1). Concurrent increases in high-density and low-density lipoprotein (HDL/ $\mathrm{LDL}$ ) and no change in the total cholesterol/HDL ratio were shown. Across P3 and LTE studies, no clinically significant changes in mean systolic or diastolic blood pressure were seen to $24 \mathrm{~m}$. Hypertension events were reported in $38(4.9 \%)$ pts: IR 4.93 [95\% Cl 3.49, 6.77]. Of these events, 4 led to pt discontinuation and 2 were serious adverse events. MACE were reported for $3(0.4 \%)$ pts receiving tofacitinib (IR 0.38 [95\% $\mathrm{Cl} 0.08,1.11]$ ) and included sudden cardiac death (57 days of exposure at time of event), myocardial infarction (197 days) and ischaemic stroke (80 days). This is within the range reported in tofacitinib studies in pts with psoriasis (IR 0.24 [0.15, 0.37]; 8,759 PY of exposure) and rheumatoid arthritis (RA) (IR 0.38 [0.30, 0.47]; 21,286 PY of exposure). No dose-dependent effects on blood pressure were apparent.

Figure. Mean \% change from baseline in lipid levels to Month 3 integrated across Phase 3 studies

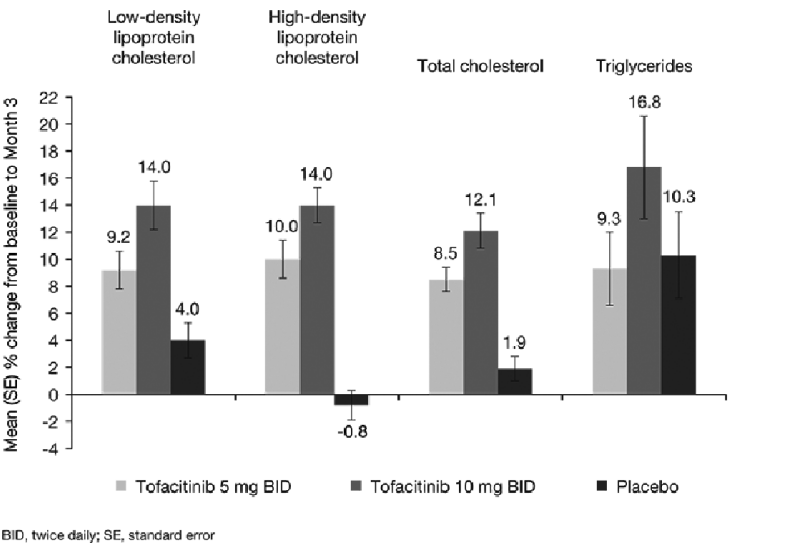

Abstract THU0299 - Figure 1. Mean\% change from baseline in lipid levels to Month 3 integrated across Phase 3 studies. BID, twice daily; SE, standard error
Conclusions: In pts with PsA, the magnitude and dose dependency of increases in lipid levels to M3 were consistent with findings in tofacitinib studies in pts with psoriasis and RA. In P3 and LTE studies, no clinically significant changes were seen in blood pressure or incidence of hypertension. Incidence of MACE was within the range reported in prior tofacitinib studies in psoriasis and RA; however, the long latency of MACE requires longer-term observation.

Acknowledgements: Study sponsored by Pfizer Inc. Medical writing support was provided by A MacLachlan of CMC and funded by Pfizer Inc.

Disclosure of Interest: D. Gladman Grant/research support from: AbbVie, Amgen, Bristol-Myers Squibb, Celgene, Eli Lilly, Janssen, Novartis, Pfizer Inc UCB, Consultant for: AbbVie, Amgen, Bristol-Myers Squibb, Celgene, Eli Lilly, Janssen, Novartis, Pfizer Inc, UCB, C. Charles-Schoeman Grant/research sup port from: AbbVie, Bristol-Myers Squibb, Pfizer Inc, Consultant for: Amgen, Gilead, Pfizer Inc, Regeneron-Sanofi, I. McInnes Grant/research support from: Celgene, Janssen, Novartis, Pfizer Inc, Roche, UCB, Consultant for: AbbVie, Celgene, Janssen, Novartis, Pfizer Inc, Roche, UCB, D. Veale Grant/research sup port from: AbbVie, Actelion, Bristol-Myers Squibb, Janssen, MSD, Novartis, Pfizer Inc, Roche, UCB, Speakers bureau: AbbVie, Actelion, Bristol-Myers Squibb, Janssen, MSD, Novartis, Pfizer Inc, Roche, UCB, B. Thiers Consultant for: Pfizer Inc, Valeant Pharmaceuticals, D. Graham Shareholder of: Pfizer Inc, Employee of: Pfizer Inc, C. Wang Shareholder of: Pfizer Inc, Employee of: Pfizer Inc, T. Jones Shareholder of: Pfizer Inc, Employee of: Pfizer Inc, R. Wolk Shareholder of Pfizer Inc, Employee of: Pfizer Inc, R. DeMasi Shareholder of: Pfizer Inc Employee of: Pfizer Inc

DOI: 10.1136/annrheumdis-2018-eular.1459

\section{THU0300 NETWORK META-ANALYSIS OF TOFACITINIB VS BDMARDS OR APREMILAST FOR THE TREATMENT OF TNF INHIBITOR-NAÏVE PATIENTS WITH PSORIATIC ARTHRITIS}

${ }^{1}$ D.D. Gladman, A.-M. Orbai ${ }^{2}$, J. Gomez-Reino ${ }^{3}$, S. Chang-Douglass ${ }^{4}$ E. Leoncini ${ }^{4}$, H.E. Burton ${ }^{4}$, K.S. Kanik ${ }^{5}$, T. Hendrikx ${ }^{6}$, J.C. Cappelleri', M.-A. Hsu' ${ }^{1}$ University of Toronto, Toronto Western Hospital, Toronto, ON, Canada; ${ }^{2} J o h n s$ Hopkins University School of Medicine, Baltimore, MD, USA $;{ }^{3}$ Hospital Clínico Universitario, Santiago de Compostela, Spain; ${ }^{4}$ Decision Resources Group, London, UK; ${ }^{5}$ Pfizer Inc, Groton, CT; ${ }^{6}$ Pfizer Inc, Collegeville, PA, USA

Background: Tofacitinib is an oral JAK inhibitor for the treatment of psoriatic arthritis (PsA)

Objectives: To perform a systematic literature review (SLR) and network metaanalysis (NMA) to evaluate the efficacy of tofacitinib 5 and $10 \mathrm{mg} \mathrm{BID}$ relative to biologic disease-modifying antirheumatic drugs (bDMARDs) or a targeted synthetic DMARD (apremilast [APR]) in tumour necrosis factor inhibitor-naïve (TNFiN) patients with active PsA.

Methods: The SLR identified randomised controlled clinical trials (RCTs) evaluating tofacitinib, bDMARDs or APR to treat patients with active PsA who were TNFiN. Outcomes included American College of Rheumatology (ACR)20 response and change from baseline in Health Assessment Questionnaire-Disability Index $(\Delta \mathrm{HAQ}-\mathrm{DI})$, Dactylitis Severity Score $(\Delta \mathrm{DSS})$ and Leeds Enthesitis Index $(\Delta \mathrm{LEI})$. Treatment effects were only evaluated during placebo (PBO)-controlled trial phases. The Bayesian NMA (with non-informative priors) was conducted using WinBUGs. The binomial logit model was used for ACR20. $\triangle \mathrm{HAQ}$-DI, $\triangle \mathrm{DSS}$ and $\Delta \mathrm{LEl}$ were analysed using the normal identify link model. A fixed-effect model was fitted to the data. Median treatment rankings represent data from each iteration of the model from which inferences are based, following model convergence.

Results: The SLR identified 25 RCTs and 21 were included in the NMA (see treatments in table 1). All trials allowed methotrexate use. PBO-controlled treatment durations ranged from 12-24 weeks. In general, patient characteristics were similar across trials. All treatments were associated with improvements in ACR2O and $\triangle \mathrm{HAQ}$-DI vs PBO. Tofacitinib $5 \mathrm{mg}$ BID was associated with substantially decreased odds ratios (ORs) for ACR20 vs golimumab 50 and $100 \mathrm{mg} \mathrm{Q4W}$, etanercept $25 \mathrm{mg} \mathrm{BW}$, infliximab $5 \mathrm{mg} / \mathrm{kg}$ and secukinumab $150 \mathrm{mg}$ QW-Q4W (table 1); ORs for all remaining comparators were not substantially different. Tofacitinib $10 \mathrm{mg}$ BID was associated with a substantially increased OR for ACR20 vs APR $20 \mathrm{mg}$ BID. Etanercept was associated with an improvement in $\triangle \mathrm{HAQ}$-DI vs tofacitinib 5 and $10 \mathrm{mg}$ BID. There was no difference in $\triangle \mathrm{HAQ}$-DI for tofacitinib vs other bDMARDs. For ACR20, tofacitinib 5 and $10 \mathrm{mg}$ BID were median ranked 14 (95\% credible interval: 8,17$)$ and $9,{ }^{5,14}$ respectively, among 18 comparators. For $\triangle \mathrm{HAQ}-\mathrm{DI}$, tofacitinib 5 and $10 \mathrm{mg}$ BID were median ranked $11^{4,13}$ and $8,{ }^{2,}$ respectively, among 14 comparators. Two studies evaluated $\triangle \mathrm{DSS}$ and $\Delta \mathrm{LEl}$; there were no substantial differences in $\triangle \mathrm{DSS}$ and $\Delta \mathrm{LEI}$ for tofacitinib 5 and $10 \mathrm{mg}$ BID vs adalimumab $40 \mathrm{mg}$ Q2W and ixekizumab $80 \mathrm{mg} \mathrm{Q2W}$ and Q4W. 